\title{
Arquivo de resistências sexílicas
}

\author{
Rafael Siqueira de Guimarães ${ }^{1}$
}

ISSN: 2350-0844

п. I2, v. I nov.2019-abr.2020

p. $159-164$.

RESUMO: Trata-se de um ensaio visual, composto por um conjunto de cinco fotos, tiradas em momentos cotidianos, com equipamento celular. As fotos são como memórias de acontecimentos-espaços que remetem às ideias de sexílio, refúgio e resistências no que tange às dissidências sexuais e de gênero.

PALAVRAS-CHAVE: Sexílio. Refúgio. Resistência.

Abstract: This is a visual essay consisting of a set of five photos taken during routine moments using a cellphone. These photos are similar to memories of events-spaces related to the ideas of sexile, refuge and resistance regarding sexual and gender dissent.

Keywords: Sexile. Refugee. Resistence.

Resumen: Este es un ensayo visual, que consiste en un conjunto de cinco fotografías, tomadas en momentos a diario, con el celular. Las fotos son como recuerdos de espacios-eventos que se refieren a las ideas de sexílio, refugio y resistencia con respecto a las disidencias sexual y de género.

Palabras clave: Sexílio. Refugio. Resistencia.

${ }^{1}$ Doutor em Sociologia e professor do Programa de Pós-graduação em Ensino e Relações Étnico Raciais, da Universidade Federal do Sul da Bahia, e do Programa de Pós-graduação em Educação, da Universidade Federal da Bahia. E-mail: rafaorlando@gmail.com 
Figura 1 - Pé da amigue tupinambá

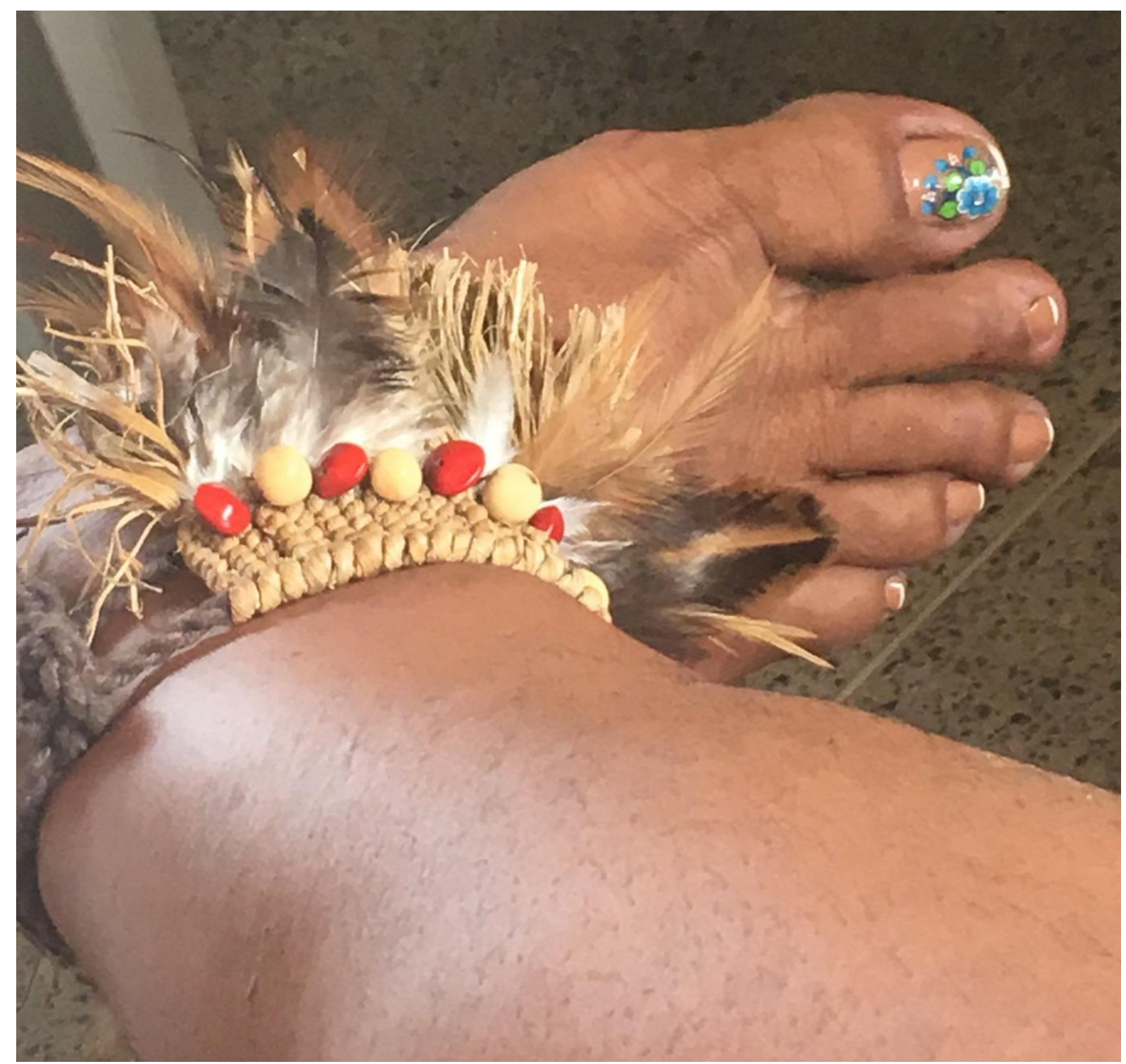

Fonte: Elaboração própria (2018)

Sentei-me pela primeira vez ao lado de Jaílson Tupinambá numa mesa de abertura de um evento em Pau-Brasil, sul da Bahia. Já estava de olho naquele pé, porque não somos criaturas puras. Pedi para sacar uma foto, ele me permitiu. Desde o olhar ocidentalizado, a norma se impõe: pode um Tupinambá marica? Sexilado, dentro e fora. 
Figura 2 - A revolução é vadia

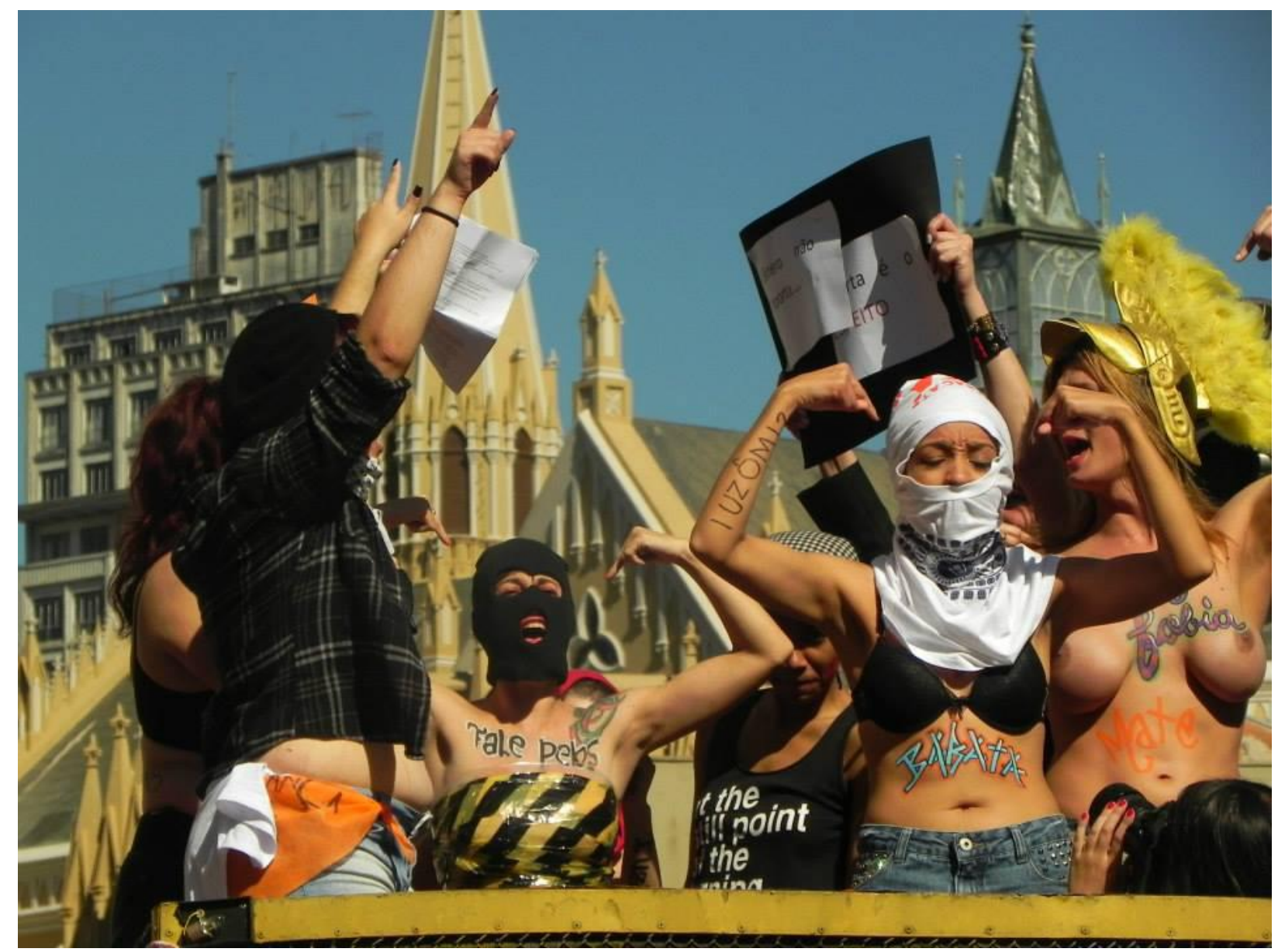

Fonte: Elaboração própria (2012)

Companheiras em marcha contra o cisheteropatriarcado racista colonial na cidade mais "genuinamente" embranquecida do país. Ai de ti, Curitiba! Era a marcha das Vadias, que também pode ser a marcha das sexiladas: pretas, trans, pardas, mestiças, indígenas, gordas, maricas, putas, vadias. O sexílio posto em marcha. 
Figura 3 - Um ponto para gozar

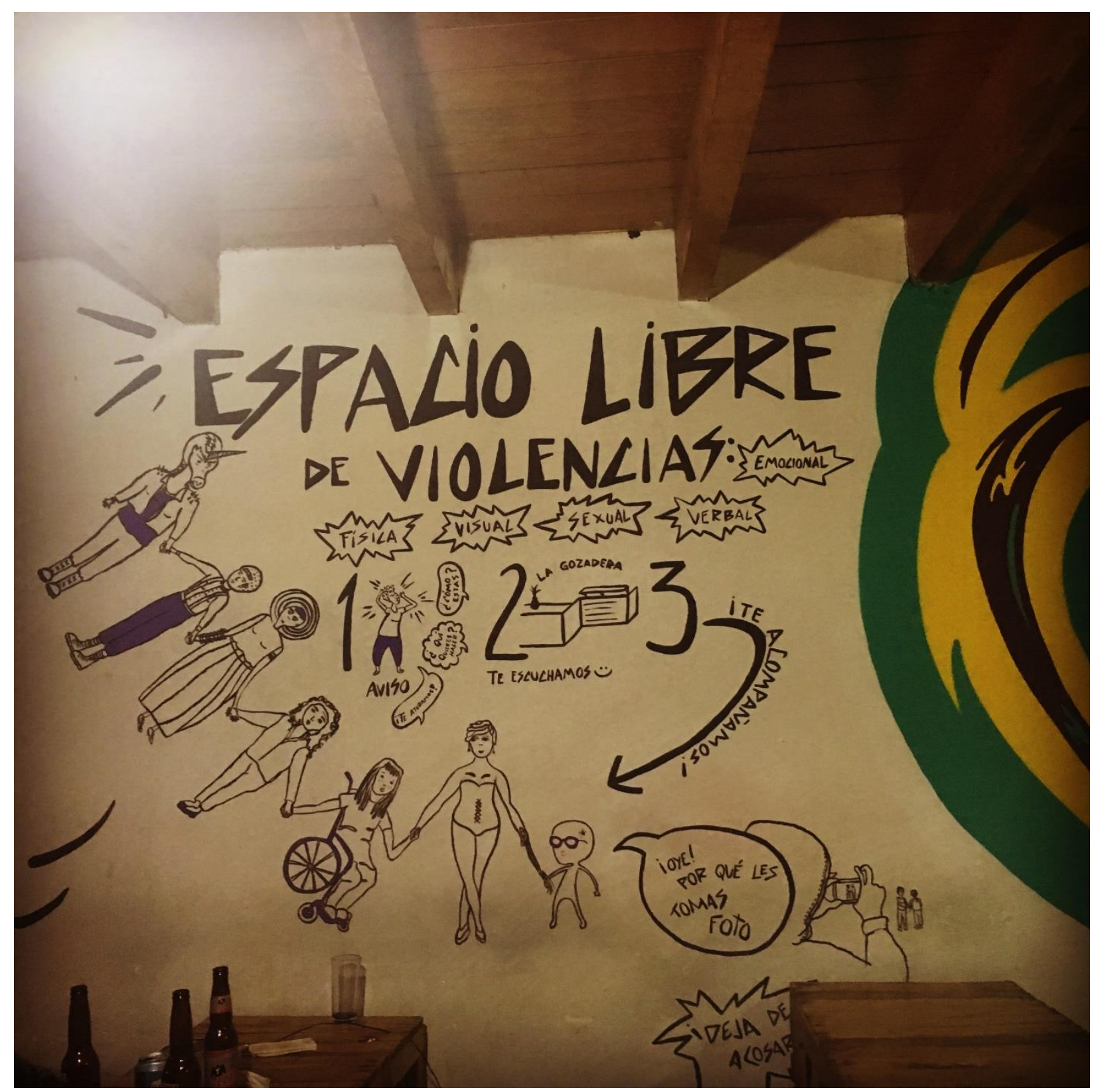

Fonte: Elaboração própria (2017)

La Gozadera, Ciudad de México. Onde zapatismo, feminismos e veganismo se entrelaçam. Um lugar de encontros culturais, políticos, de comer e gozar. Neste lugar, que fica no coração da cidade, os feminismos e as dissidências de gênero e sexuais se encontram com a lutas originárias e as guerrilhas. É um espaço de refúgio, de acolhimento a quem vive o sexílio de muitas formas. Nas paredes, nos banheiros, na comida: diferença, luta, respeito. 
Figura 4 - Nosso corpo é sagrado

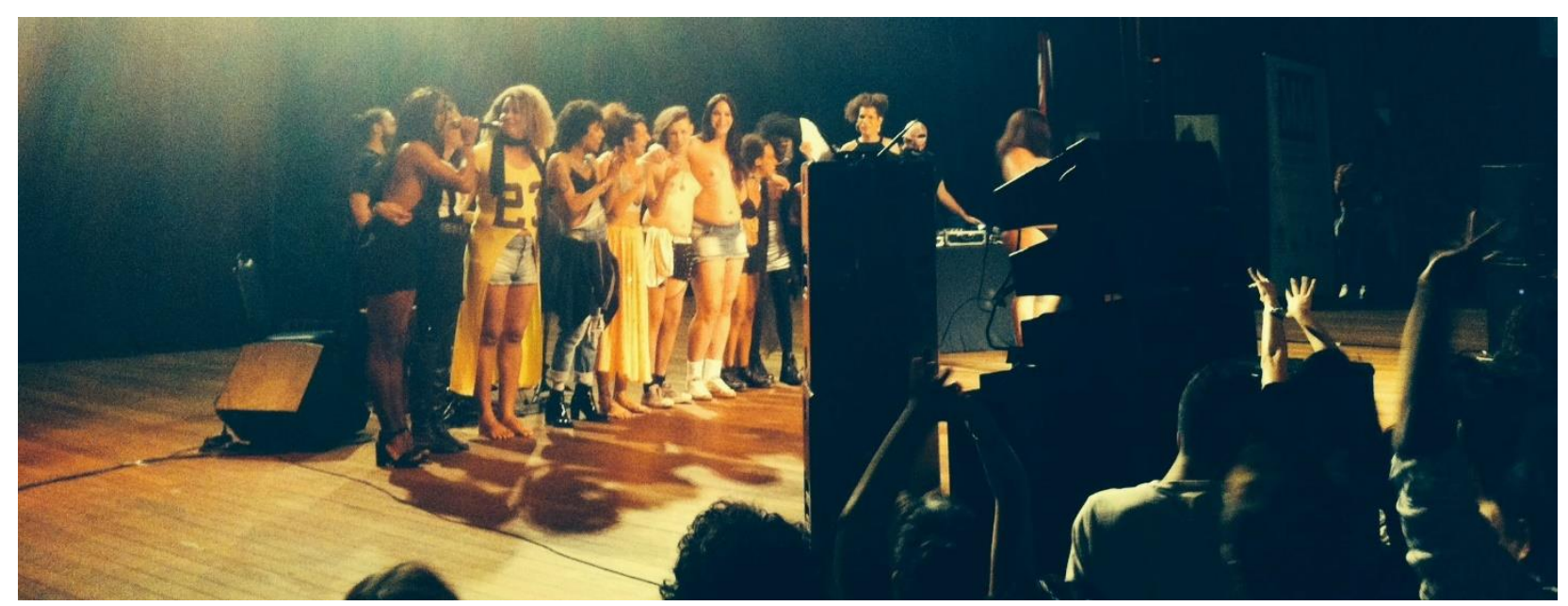

Fonte: Elaboração própria (2017)

Linn da Quebrada convida todas as travestis ao palco, durante o Fazendo Gênero, em Florianópolis. Anuncia que travesti é sagrada, disse que é possível estar "desfazendo gênero", referência a outro evento e ao texto de Judith Butler. Diz isto num contexto em que a organização do evento havia disponibilizado poucos ingressos para pessoas transvestigêneres, o que, de última hora, foi mudado. Espaço de resistência, espaço de luta, dentro da Universidade, acolhimento ao sexílio, um refúgio, ainda que efêmero, ao CIStema. 
Figura 5 - LáEle

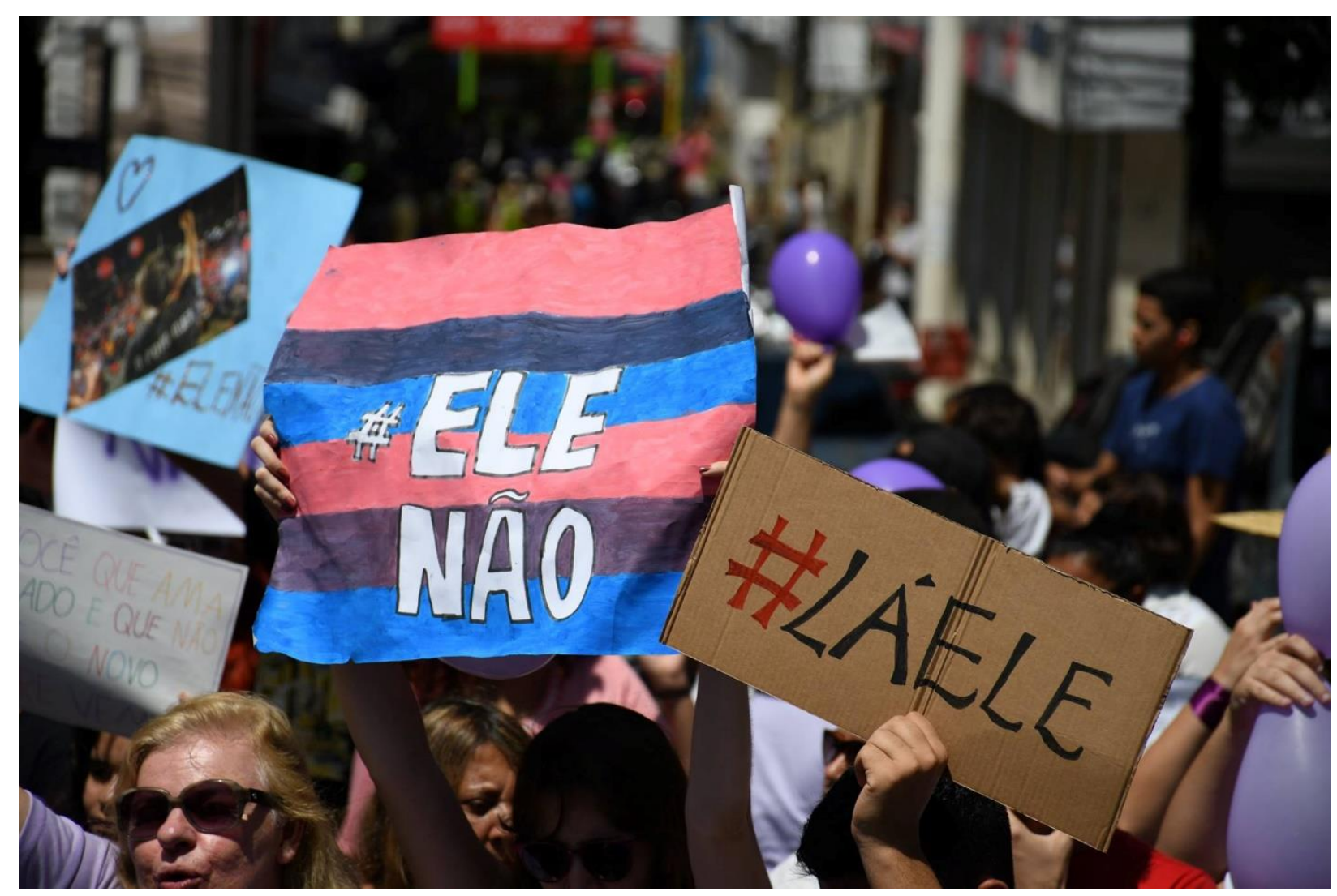

Fonte: Elaboração própria (2018)

Ilhéus, sul da Bahia. Foi na Marcha do \#Elenão que vi, pela primeira vez, publicamente na cidade, alguma referência à inclusão da pauta de pessoas trans. A bandeira, pintada com as cores do movimento trans, carregada entre tantas pluralidades, protagonizada por um coletivo amplo de mulheres da cidade. Houve ataques machistas durante e após a marcha. Resistência sexílica posta em referência no interior do acontecimento, com a faixa no dizer ao modo baianês. Cruce de fronteiras. 